\title{
Improved sonic echo method with multiple receivers and amplifier to evaluate the length of capped piles
}

\author{
Shu-Tao Liao' ${ }^{1}$, Chih-Peng Yu ${ }^{2 *}$ Jian-Hua Tong ${ }^{3}$, Jiunnren Lai ${ }^{4}$, \\ Ching-Tien Chang ${ }^{1}$ \\ ${ }^{1}$ Department of Civil Engineering, Chung Hua University, Hsinchu, Taiwan \\ ${ }^{2}$ Department of Civil Engineering, National Chung-Hsing University, Taichung City, \\ Taiwan \\ ${ }^{3}$ Department of Computer Science \& Information Engineering, Hungkuang University, \\ Taichung City, Taiwan \\ ${ }^{4}$ Department of Construction Engineering, Chaoyang University of Technology, \\ Taichung City, Taiwan
}

\section{OPEN ACCESS}

Received: January 26, 2021

Revised: March 9, 2021

Accepted: March 11, 2021

Corresponding Author:

Chih-Peng $\mathrm{Yu}$

cpyu@nchu.edu.tw

(c)

Creative Commons Attribution License (CC BY 4.0), which permits unrestricted distribution provided the original author and source are cited.

Publisher:

Chaoyang University of

Technology

ISSN: $1727-2394$ (Print)

ISSN: 1727-7841 (Online)

\begin{abstract}
Using nondestructive testing techniques to evaluate the length of a pile in a capped pile group is always an important issue for its high value of potential applications. One of the applicable occasions is to decide whether the underneath piles of a capped pile group are broken after the attack of severe earthquakes. There seems no economically feasible way at current stage to achieve this goal for capped piles. In this paper the essence of this difficulty is further illustrated with the results of the sonic echo tests carried out before and after a pile was capped. Then a new method utilizing the traditional sonic echo test incorporated with multiple receivers is proposed to approach the solution of this kind of problems. The idea of this method is to calculate the difference of the response signals obtained in the receivers so that the interferences from the pile cap may be reduced or eliminated and then the differenced result is exponentially amplified for identifying possible reflections from the pile toe. Numerical simulations using finite element models and a field test on a miniature pile group were carried out to study the feasibility of this new method.
\end{abstract}

Keywords: Nondestructive test, Capped pile, Sonic echo test, Multiple receivers.

\section{INTRODUCTION}

A disastrous earthquake with a magnitude of 7.3 in Richter scale struck central Taiwan on September 21, 1999. The post-earthquake evaluation on the integrity of the structures played an important role in the success of the later retrofitting work (Tong et al., 2007; Tong et al., 2010; Liao et al., 2006; Yu and Liao, 2006; Lai et al., 2005). In this aspect, the determination of the substantial length of a pile exhibits a high value in practical application, particularly when evaluating the integrity of existing foundations such as piles with cap. To evaluate the substantial length of a pile, nondestructive testing (NDT) technologies are usually regarded as a safe and economic way. However, at present time this kind of technologies was usually applied only for uncapped piles, but not for capped piles because of the complicated nature of the problem.

Among the most frequently used NDT methods, the sonic echo (SE) and impact response (IR) methods have long been recognized as the direct and reliable methods for evaluating the length of uncapped piles (ASTM, 2004; Olson et al., 1995). Many successful cases have been reported with these methods (Wang, 2020; Ni et al., 2019; Davis, 2003; Chow et al., 2003; Kim et al., 2002; Finno and Gassman 1998; Liao and 
Roesset, 1997; Rausche et al., 1991; Baker et al., 1991). However, rare reports on predicting the length of capped piles can be found due to the profound difficulty (Yu, 2019; Guddati et al., 2018; Baxter et al., 2004; Gassman and Finno, 1999; Gassman and Finno, 2000). For this reason, the nondestructive testing of piles is practically categorized into accessible-head and inaccessible-head cases, based on the nature of difficulty.

In 1999, the IR method was extended to include receiving signals with multiple geophones to overcome the difficulty in the inaccessible-head cases (Gassman and Finno, 1999). To minimizing the interfering effects of surface wave reflections in pile cap, the signal processing idea to obtain composite signals of multiple receivers was proposed in this paper. The composite signals were obtained by averaging the velocity-time traces acquired from four geophones. These data in the time domain were then transformed to and processed in the frequency domain so that the mobility curves can be presented for interpretation. Later in 2004, Baxter and Gassman presented the comparison of the results of the IR tests on drilled shafts with finite element models and experiments. Recently, a frequency domain approach, which utilizes laterally induced IR signals, was reported to have potentials in recovering the length of capped piles ( $\mathrm{Yu}$, 2019). However, the idea requires excavation so that the impacting experiments can be performed on the side of the capped pile. One common conclusion of these research efforts demonstrated again that evaluating the length of capped piles is still a very difficult issue which requires much further study. However, these previous efforts have greatly advanced the solution to this difficult problem.

At present time, most of the reported articles placed the focus on the IR method and interpreted the obtained data in the frequency domain (Yu et al., 2020). In this paper, the SE method and the data in the time domain are selected for studying the feasibility of predicting the length of capped piles. In the contexts to follow, the philosophy of the SE method will be first introduced. The difference and difficulty for evaluating the length of uncapped and capped piles will then be illustrated by an in situ case so that the profound difficulty involved in the cases of capped piles may be more understood. Finally a new method utilizing the SE method will be proposed by this research. The idea of using multiple receivers for response differences and a helpful amplification technique will be incorporated into the SE method so that the length of a capped pile may be evaluated in a favored fashion.

\section{SONIC ECHO METHOD}

To carry out a SE test on a pile, the pile head is struck at its center by an instrumented hammer and the response of the pile is recorded with a receiver placed at a nearby location, as shown in Fig.1. The recorded response can be the particle displacement, velocity, or acceleration, as a function of time at the location of the receiver. The next step is to identify the signal associated with the stress wave that travels from the impacted point, is reflected at the pile toe and travels back to the receiver. The length $L$ of the pile can then be estimated using this traveling time $\Delta t$ and the longitudinal stress wave velocity $V_{L}$. In most cases when one-dimensional wave propagation prevails, this velocity is calculated by $V_{L}=\sqrt{E / \rho}$, where $E$ and $\rho$ are the Young's modulus and mass density of the pile. This kind of NDT methods is also categorized as the surface reflection methods for the signals to be studied are the reflections of the induced stress waves and the receivers are located at accessible areas.

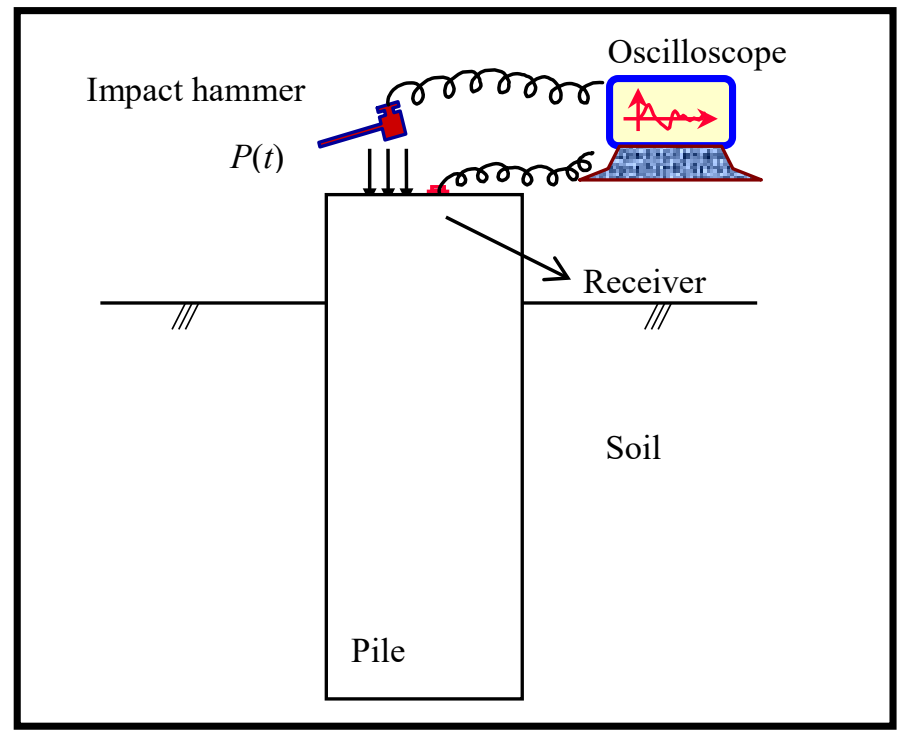

Fig. 1 Schematic showing sonic echo test on an uncapped pile 


\section{International Journal of Applied Science and Engineering}

Liao et al., International Journal of Applied Science and Engineering, 18(3), 2021028

\section{DIFFERENT RESPONSES OF UNCAPPED AND CAPPED PILES}

Using the sonic echo method mentioned above, the length of an uncapped pile can be directly estimated with efficiency and accuracy. This practice can be applied to the quality control of newly-built piles before the cap (or foundation plate) is installed. However, after the cap is installed as shown in Fig. 2, the situation is much difficult.
To gain an insight into this problem, a research project was launched to study the difference of the responses of an in-situ pile before and after it was grouped with a pile cap. Shown in Fig. 3 is the top view of a pier foundation designed for a new bridge across a river near Holon, a town area in central Taiwan. The pier is supported by seven piles with a rectangular cap of $11 \mathrm{~m}$ in length, $5 \mathrm{~m}$ in width, and $2.5 \mathrm{~m}$ in thickness. The designed diameter and the length of each pile are $1.2 \mathrm{~m}$ and $14 \mathrm{~m}$, respectively. They were designed as friction piles and constructed in casings. The pile located at the upper left corner in Fig. 3 was selected for the study of

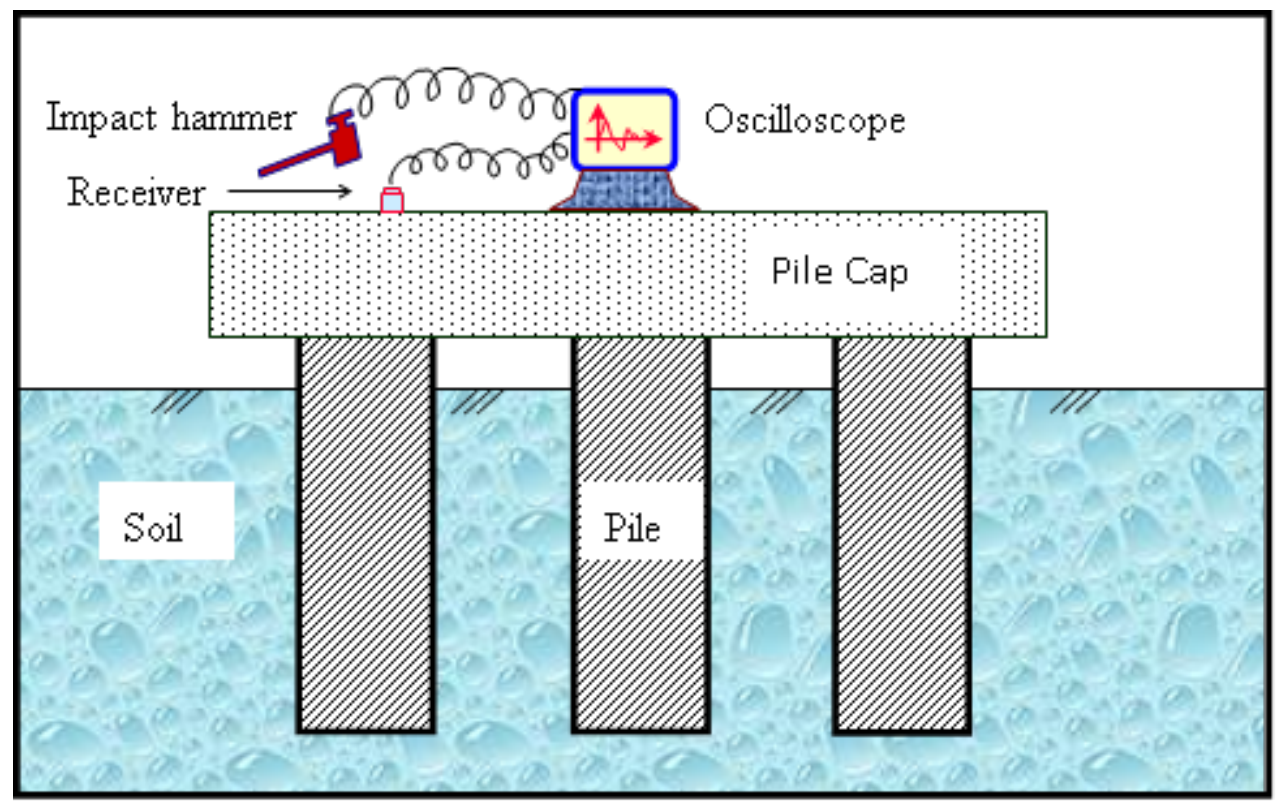

Fig. 2. Schematic showing Sonic Echo test on a capped pile group

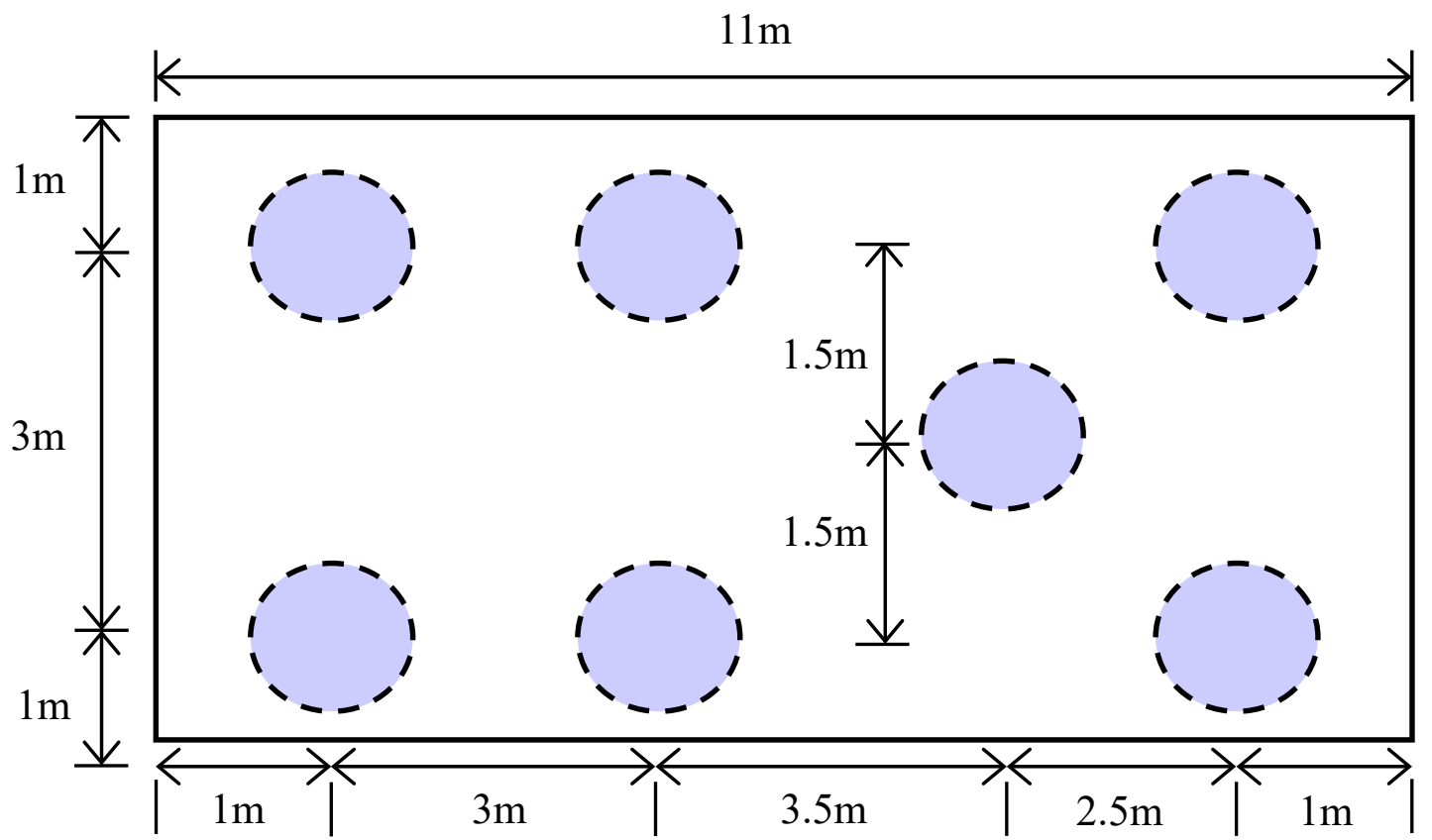

Fig. 3. Schematic showing the top view of an in situ pier foundation supported by a capped pile group with seven piles 


\section{International Journal of Applied Science and Engineering}

Liao et al., International Journal of Applied Science and Engineering, 18(3), 2021028

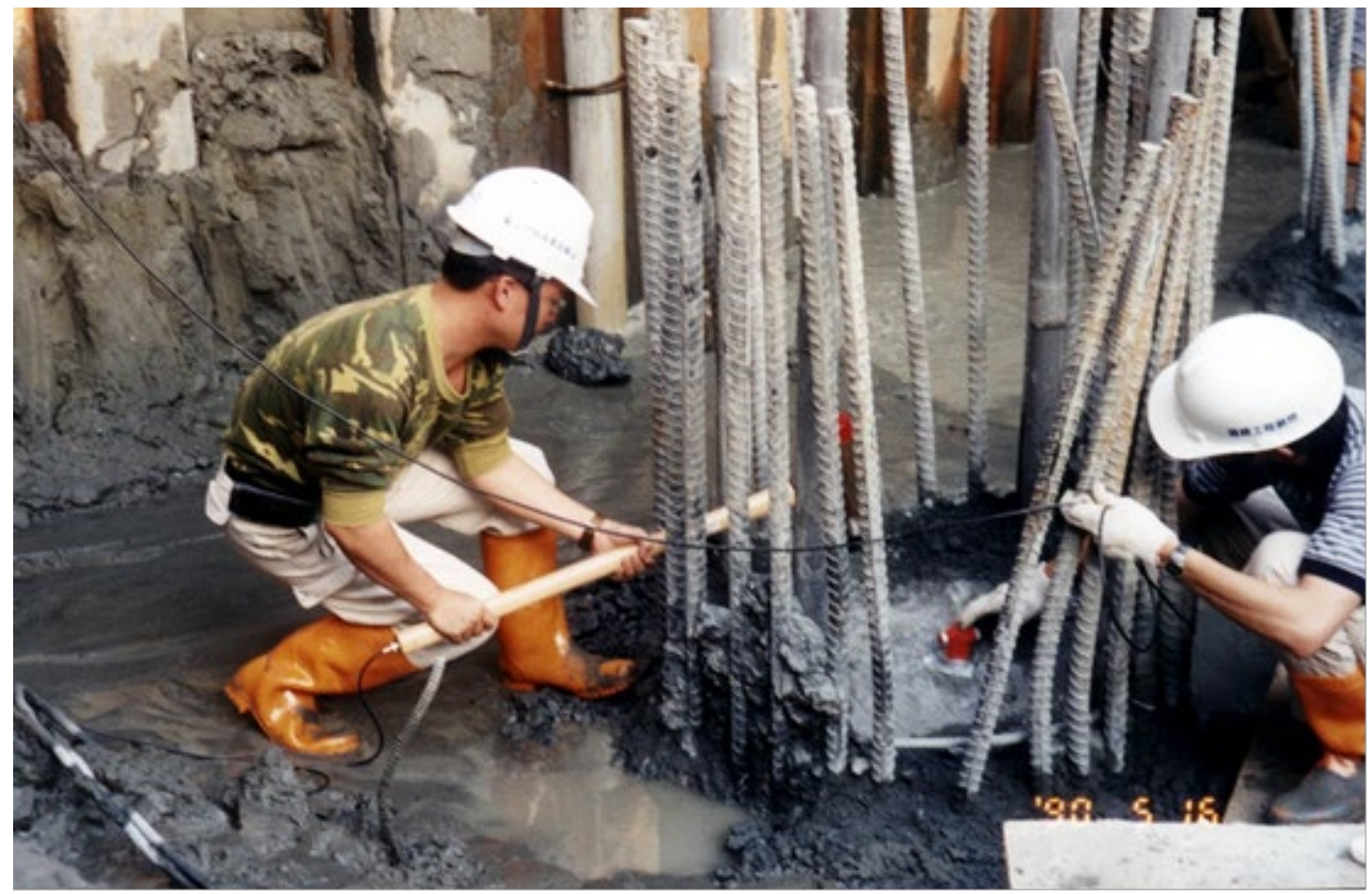

Fig. 4. Photo of a sonic echo test on the head of a pile before it is capped

\begin{tabular}{cccccc}
\hline & Concrete & \multicolumn{2}{c}{ Gravel } & Silty fine sand & Unit \\
\hline$E_{\mathrm{c}}$ & $3.31 \times 10^{10}$ & $E_{\mathrm{s}}$ & $6.12 \times 10^{8}$ & $5.18 \times 10^{7}$ & $\mathrm{~N} / \mathrm{m}^{2}$ \\
$\rho_{c}$ & 2300 & $\rho_{s}$ & 2200 & 2037 & $\mathrm{~kg} / \mathrm{m}^{3}$ \\
$v_{c}$ & 0.2 & $v_{s}$ & 0.3 & 0.4 & - \\
$V_{S}$ & 2450 & $V_{S}$ & 327 & 95 & $\mathrm{~m} / \mathrm{s}$ \\
$V_{L}$ & 3800 & $V_{L}$ & 527 & 159 & $\mathrm{~m} / \mathrm{s}$ \\
\hline
\end{tabular}

this research. Before the pile cap was installed, a SE test was carried out on the pile. Fig. 4 shows that the pile head was struck by an instrumented hammer while a receiver was placed at about half a radius of the pile to record the response of the pile at the location. The test was performed 28 days after concrete placement and hence normal properties and strength of concrete was assumed. Listed in Table 1 are the material properties and associated stress wave velocities of the concrete in the pile. Using the Young's modulus $E_{\mathrm{c}}$, mass density $\rho_{c}$, and Poisson ratio $v_{c}$ of the concrete in the table, the longitudinal wave velocity of the pile can be calculated to be $V_{L}=3800 \mathrm{~m} / \mathrm{s}$. The velocity of shear stress wave $V_{S}$ is also listed in the table for reference.

The time history of the velocity amplitude obtained from the SE test in situ is presented in Fig. 5 with a solid curve. In analyzing the results of a SE test, a sudden rise in the oscillation amplitude usually implies the arrival of a reflected wave, which may be used to retrieve the distance to a boundary, interface, or abnormality. Using this useful rule, it is easy to identify that the first arrival time of the stress waves reflected at the pile toe and traveled back to the receiver at the pile head is about $0.0168 \mathrm{~s}$, which is marked with $t_{b}$ in the figure. Consider that the stress waves leave the pile head at a time of $0.0092 \mathrm{~s}$ (marked with $t_{a}$ in the figure). The pile length can be determined to be $L=14.4 \mathrm{~m}$. The error for this prediction to the designed length of the pile is only about $3 \%$.

To gain an in-depth understanding of this kind of problem, the finite element (FE) model was also used to simulate the SE test over this pile. To approach the practical conditions as close as possible, the in situ soil profile and the impact force were incorporated into the model. Shown in Fig. 6 with a solid curve is the in situ impact force, which is simulated in the FE model with the following function:

$$
\begin{aligned}
P(t) & =-P_{0} \sin ^{2} \omega\left(t-t_{1}\right) & & \text { for } t_{1} \leq t \leq t_{2} \\
& =0 & & \text { otherwise }
\end{aligned}
$$




\section{International Journal of Applied Science and Engineering}

Liao et al., International Journal of Applied Science and Engineering, 18(3), 2021028

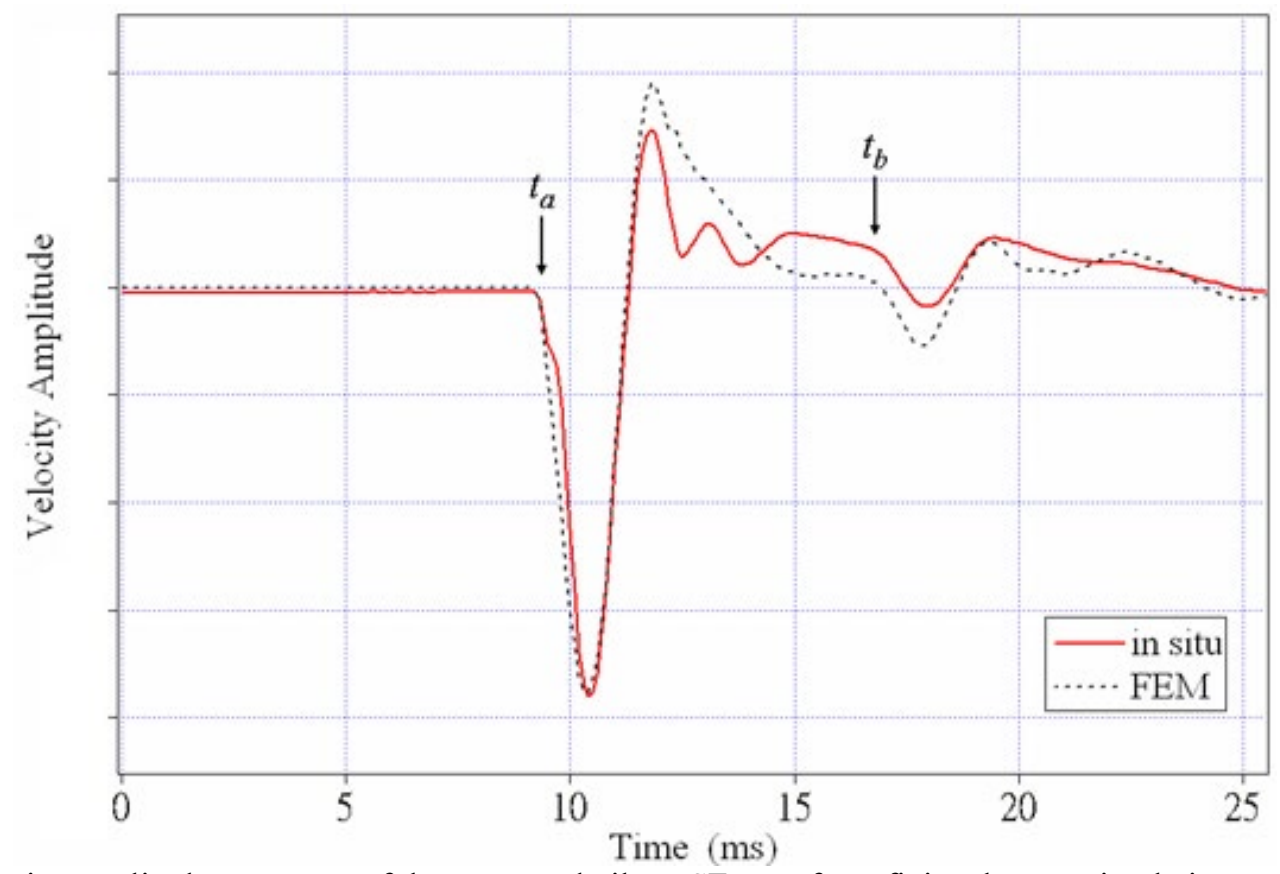

Fig. 5. Velocity amplitude responses of the uncapped pile to SE tests from finite element simulation and in situ test

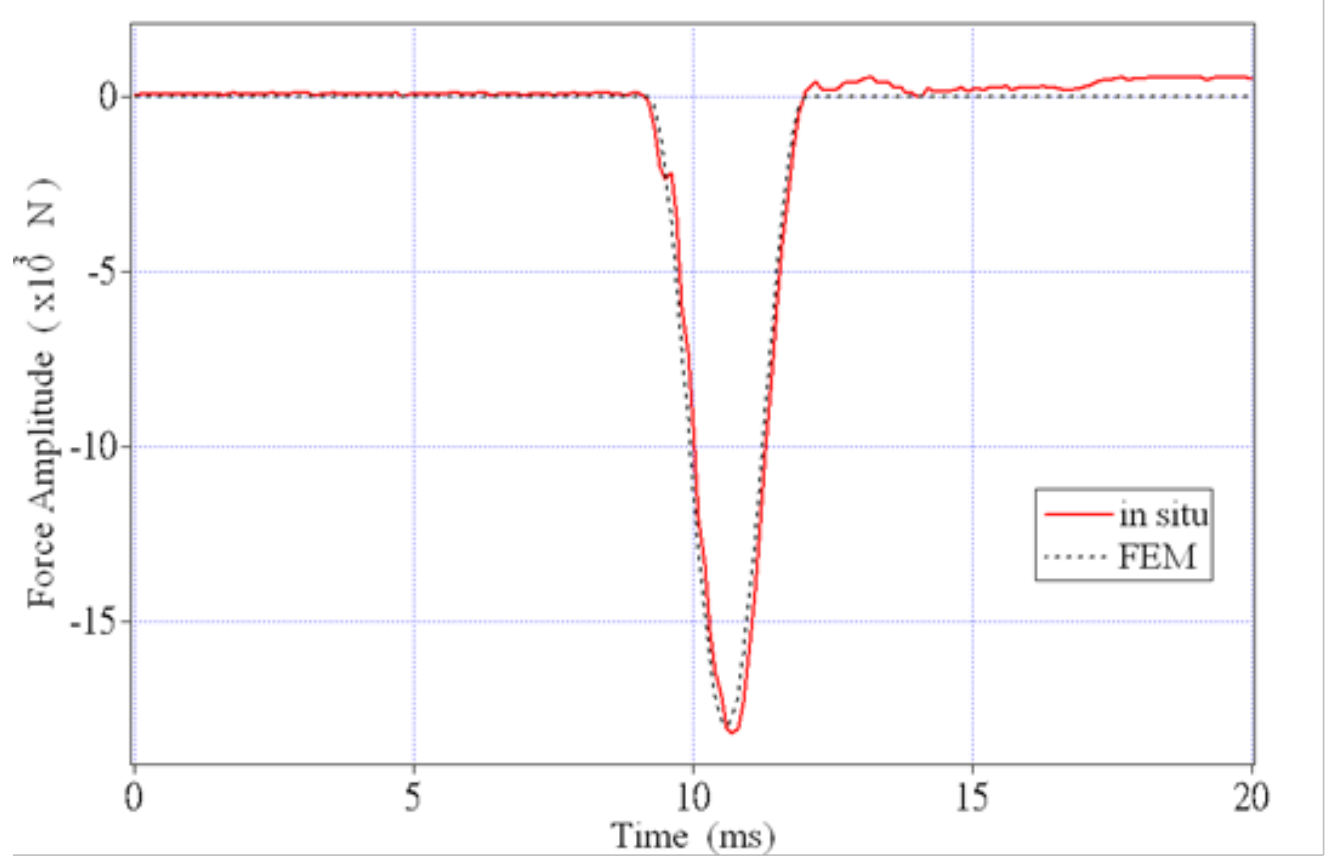

Fig. 6. In situ measurement and numerical simulation of the impact force functions used in the SE test

where $t_{1}=9.2 \times 10^{-3} \mathrm{~s}=9.2 \mathrm{~ms}, t_{2}=12 \mathrm{~ms}, P_{0}=18000 \mathrm{~N}$, and $\omega=\pi / T_{\mathrm{d}}$, in which $T_{\mathrm{d}}=t_{2}-t_{1}$ is the duration of the impact force. This is the square of a half of a sinusoidal function with the duration of $2 T_{\mathrm{d}}$. This simulated force is also plotted in Fig. 6 with a dashed curve for comparison. It can be seen that the simulation function and the in situ history of the force are very close. From the boring data, the in situ soil is modeled with gravel formation from 0 to $7 \mathrm{~m}$ in depth, silty fine sand from 7 to $18 \mathrm{~m}$, and gravels below
$18 \mathrm{~m}$ again. Here the ground was leveled with the top surface of the pile. The Young's modulus $E_{\mathrm{s}}$, mass density $\rho_{s}$, and Poisson ratio $v_{s}$ of the gravel and the silty fine sand layers used in the FE model are listed in Table 1. The results of the FE model are plotted with a dashed curve in Fig. 5 for comparison. Good match between the results obtained in situ and from the numerical model can be observed from this figure. 


\section{International Journal of Applied Science and Engineering}

Liao et al., International Journal of Applied Science and Engineering, 18(3), 2021028

Later as the pile cap was installed, the SE test was carried out again in attempt to assess the length of the same pile. Before the SE test, a direct transmission test over the length of the cap was done to obtain the propagation velocity of the longitudinal stress waves in the cap, which was determined to be $2940 \mathrm{~m} / \mathrm{s}$, a value far below that for a concrete material of normal strength. The reason for this phenomenon is that the test was carried out just 14 days after the concrete was placed for the cap because of the tight construction schedule. On the same day, the SE test on the capped pile was implemented. Fig. 7 shows that the hammer and the receiver were applied on the top surface of the pile cap over a region beneath which the original pile under study is located. The velocity time history obtained in situ is presented with a solid curve in Fig. 8. The FE simulation result is also plotted with a dashed curve in Fig. 8 for comparison. From the figure it is seen that the stress waves leave the impacted point at about $t_{a}=10.2 \mathrm{~ms}$. Knowing that the thickness of the cap is $2.5 \mathrm{~m}$ and the length of the pile is $14 \mathrm{~m}$, the travel time of the waves reflected from the pile toe can be estimated to be $9.1 \mathrm{~ms}$ for the propagation velocities of the stress waves over the cap and pile regions are 2940 and 3800 $\mathrm{m} / \mathrm{s}$, respectively. Therefore the theoretical first arrival time of the reflected waves should be $t_{b}=19.3 \mathrm{~ms}$. However, from the response on the time there is almost no identifiable sign representing the reflection. But now only an amplitude rise can barely encountered on the time of $t_{c}=20.3 \mathrm{~ms}$ as we trace the evenly-attenuating oscillations in the response curve. With this arrival time, the length of the pile can be determined to be $16 \mathrm{~m}$. The error for this prediction now jumps to be $14 \%$ as compared to the $3 \%$ for the case of the uncapped pile. Comparing Fig. 5 and Fig. 8 indicates that the existence of pile cap seriously complicates the results of $\mathrm{SE}$ tests. The phenomenon is mainly due to that the response signals associated with the reflections from the pile toe is overwhelmed by that associated with the reflections bouncing in the pile cap and the free vibrations of the pile cap. Based on this knowledge, a new strategy is proposed in this paper to approach the solution. The main idea is to use the multiple receivers in the SE test so that the unwanted reflections bouncing in the cap may be filtered out by subtracting the received signals. An amplification technique is then applied to the remaining signals so that the reflections from the pile toe may be clearly exposed.

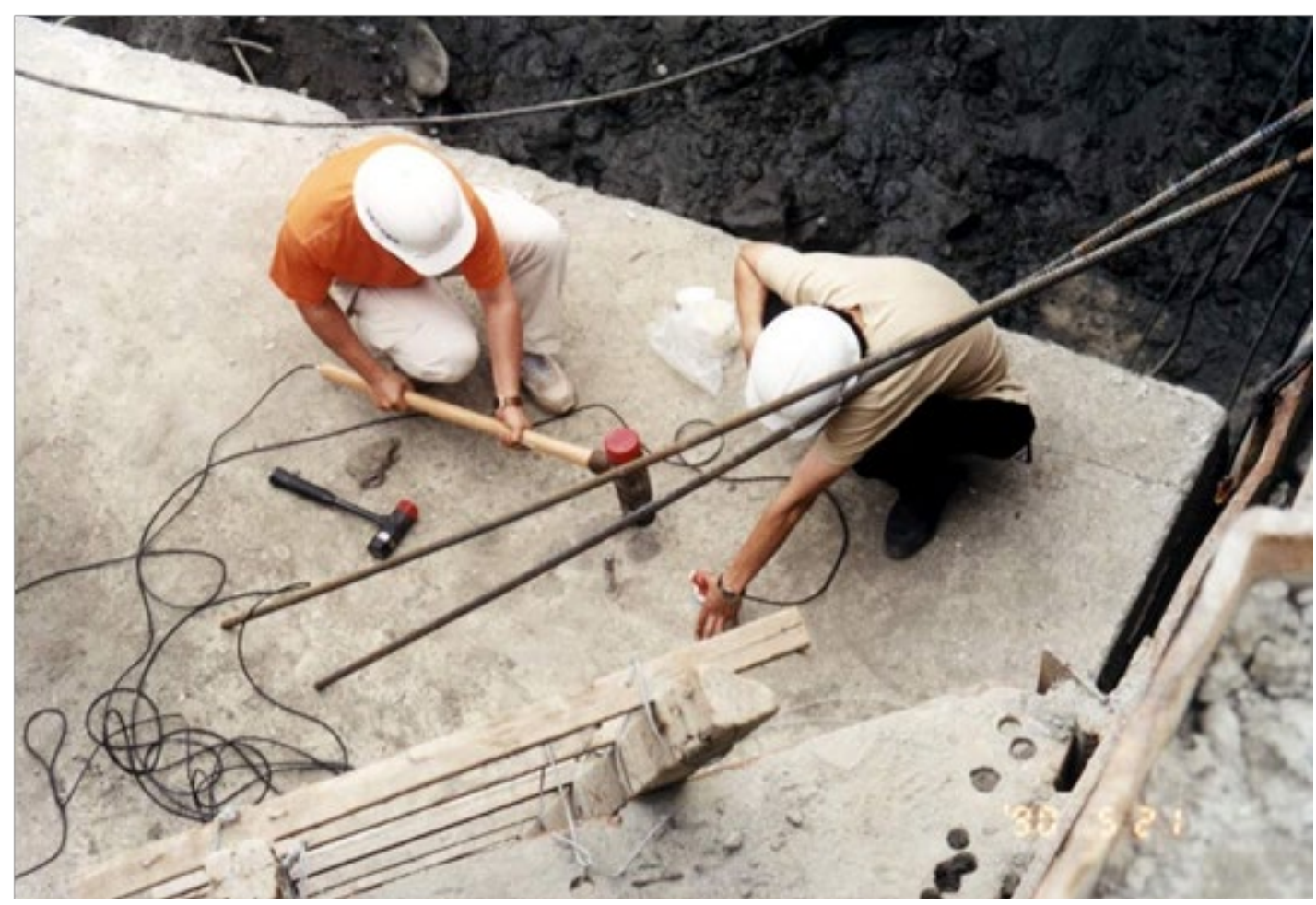

Fig. 7. Photo of a sonic echo test on a capped pile group 


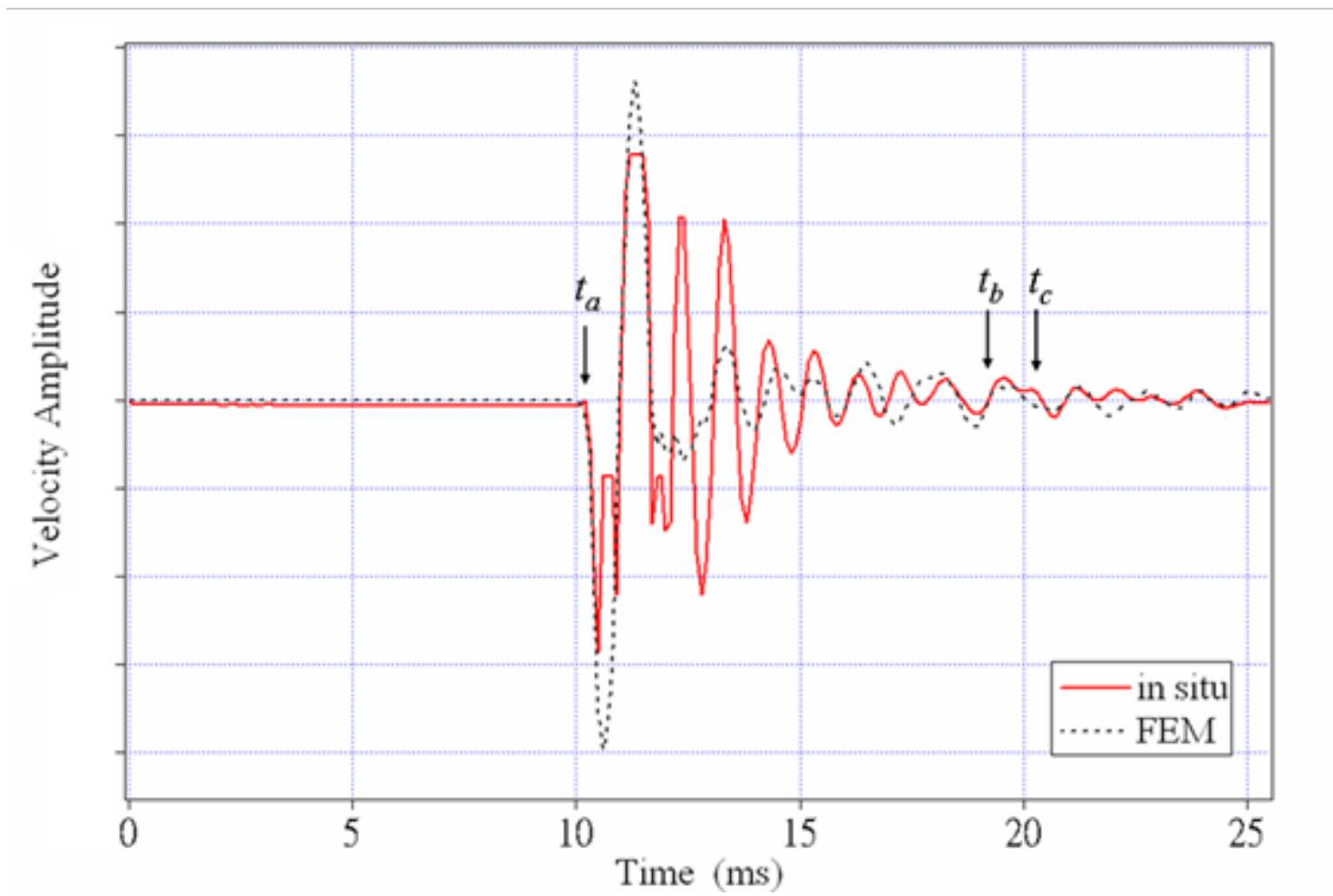

Fig. 8. Velocity amplitude responses of the capped pile to SE tests from finite element simulation and in situ test

\section{ARRANGEMENT OF MULTIPLE RECEIVERS}

Based on the attempt to eliminate the unwanted reflections bouncing in the pile cap, the use of multiple receivers was proposed in this study. The initial thought can be illustrated by using the ray path theory, which is only a simplified manifestation for the complicated phenomenon of $3 \mathrm{D}$ stress wave propagation. However, this indeed is not far from the real condition in testing piles by SE method because the wave length of the stress waves introduced into a pile in a SE test is usually very large compared to the diameter of the pile and therefore the propagation of 1D longitudinal wave prevails. To illustrate the philosophy of the proposed method, consider a capped pile subjected to a SE test as shown in Fig. 9. It is noted that stress waves reflect at interface where the mechanical impedance of the medium changes. In this case such interfaces exist at the bottom surfaces of the cap and of the pile. Therefore the receivers located at the top surface of the cap will detect the arrivals of reflections from two major interfaces, i.e., the bottom surfaces of the cap and of the pile. Referring to Fig. 9, Receiver 1 and Receiver 2 represent two receivers selected respectively from each of the two groups of receivers which are placed at the top surface of the cap within and outside, respectively, the region projected by the underneath pile. With such arrangement, it is expected that the testing responses collected in Receiver 1 will be abundant in the reflections from both the bottom surfaces of the cap and of the pile, while those in Receiver 2 will be abundant major in those from the bottom surface of the cap. It is thus expected that subtracting the signals recorded in these two receivers may filter out the reflections from the bottom surface of the cap and the desired reflections from the pile toe may be extracted. The remaining signals after this manipulation are then exponentially amplified with time so that the arrival of the reflections from the pile toe may be clearly exposed.

\section{EXPONENTIAL AMPLIFICATION OF SIGNALS}

To compensate the geometric damping effect as stress waves are introduced into a semi-infinite medium to detect any implied inhomogeneity with the reflections, exponential amplification techniques were frequently used. After many trial studies by the authors a very helpful one was adopted by this proposal. The general form of the adopted amplification function is defined by

$$
f=\left(A^{x}+A^{-x}\right)^{2}
$$

where $f$ is the amplification factor applied to the amplitude of the signal at time $T, x=t / T$ is the normalized parameter with $0 \leq t \leq T$, and $(T, F)$ is the coordinates of the rightmost point of the amplification curve and hence $F=\left(A+A^{-1}\right)^{2}$. Note that the value of the amplification is $f=F$ for $x \geq 1$. Shown in Fig. 10 is an example of the amplification curve with $A=3$. Here the point $(T, F)$ is usually assigned by the analyst so that the amplification effect on the obtained 


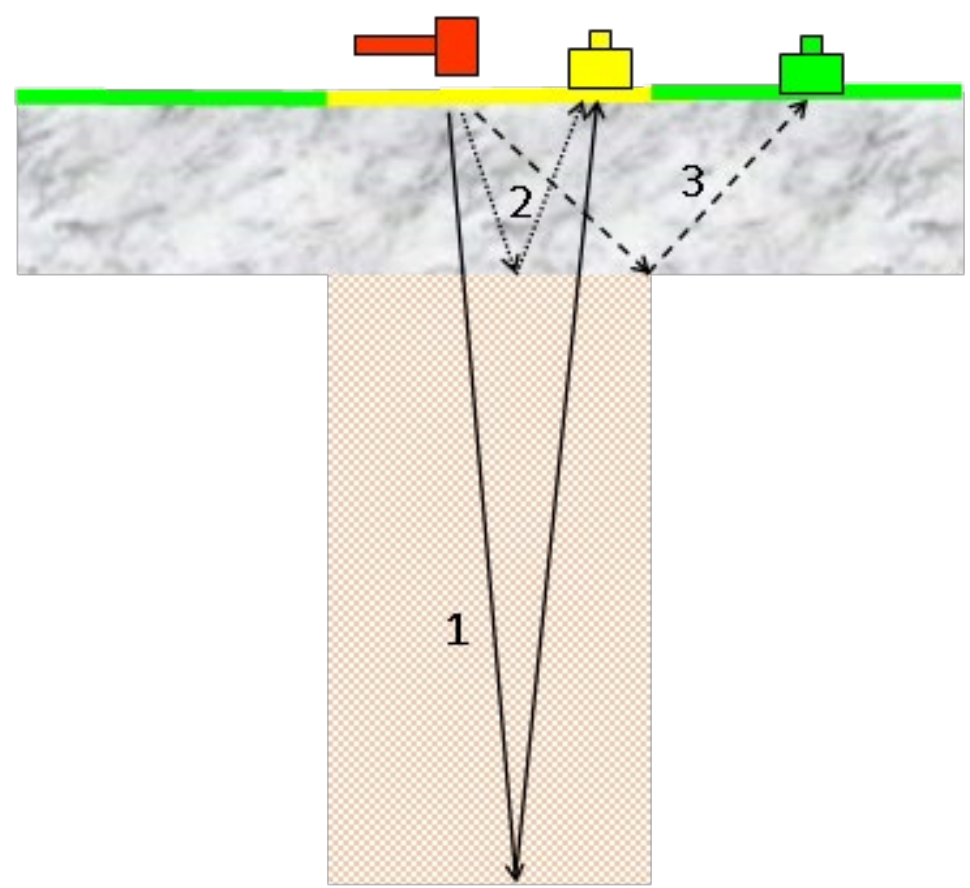

Fig. 9. Schematic showing traveling paths of stress waves in the pile and cap

signals may be assessed for searching for significant reflections. To achieve this goal, a Windows program was designed in this research project to allow the analyst to define any amplification curve of this form by dynamically allocating the point $(T, F)$ with the computer mouse. The program was then equipped with the capability of continuously dynamic allocation by dragging the mouse in the window. Theoretically speaking, the echo from the pile toe can be discovered from the response curve by careful observation and comparison as the curve is amplified gradually through time axis by dragging the mouse along any horizontal line in the window.

\section{RESULTS OF NUMERICAL SIMULATION}

In order to study the feasibility of the proposed scheme, the numerical simulation was first developed. Shown in Fig. 11 is the top view of the finite element model for a capped pile as shown in Fig. 9. The length, width, and thickness of the cap are all $2.5 \mathrm{~m}$. The diameter and length of the pile beneath the cap are $1.2 \mathrm{~m}$ and $14 \mathrm{~m}$, respectively. The surrounding soil is modeled with gravel formation from 0 to $7 \mathrm{~m}$ in depth, silty fine sand from 7 to $18 \mathrm{~m}$, and gravels below $18 \mathrm{~m}$ again. Here the ground is leveled with the top surface of the cap. The elastic properties of the soil used in the FE model are listed in Table 1. Five receivers, as denoted by $P_{0}$ to $P_{4}$ in Fig. 11, were placed on the top surface of the pile cap to record the responses of the SE test. It can be seen that $P_{0}$ is located within the region projected by the underneath pile and $P_{2}$ to $P_{4}$ are outside this region. $P_{1}$ is just on the border line of this region. To study the effect of the relative locations of the two receivers selected for subtracting the signals, the relative displacements obtained by subtracting each of the displacements at the receivers $P_{1}$, $P_{2}, P_{3}$, and $P_{4}$ from that at the receiver $P_{0}$ are plotted together in Fig. 12. It can be seen that the result associated with the pair $P_{0}$ and $P_{4}$ exhibits more clear profile for observation. The reason for this phenomenon may lie on the fact that is located far outside the region projected by the underneath pile therefore the effect of subtraction can be enhanced. In the followings, this pair is therefore selected for further processing to illustrate the proposed scheme of this paper. The $(x, y)$ coordinates of the two receivers at $P_{0}$ and $P_{4}$ are respectively $(0.284,0.164)$ and $(1.007,1.007)$ in meters if the $x y$-plane lies on the top surface of cap and centered at the axis of the pile.

Shown in Fig. 13 (a) is the original result by subtracting the displacement response history obtained in Receiver $P_{4}$ from that obtained in Receiver $P_{0}$ so that the interference of the reflections in the cap can be reduced. Note that the new time axis is measured from the first peak of the resultant curve to make it straightforward the later work of evaluating the travel time of the reflection from the pile toe. This original displacement difference can then be amplified by the amplification functions defined in Equation (2) so that possible reflections from the pile toe can be sought. This can be usually achieved by dragging the cursor along a horizontal line in the figure for continuously defining the control points of the amplification functions so that the amplified curve may be carefully examined for possible reflections. Presented in Fig. 13 (b) to (d) is the amplified curve as the amplification control point is dragged onto a time $t=4,6$, and $8.8 \mathrm{~ms}$, respectively. In this process of searching, a significant sudden rise in the oscillation 


\section{International Journal of Applied Science and Engineering}

Liao et al., International Journal of Applied Science and Engineering, 18(3), 2021028

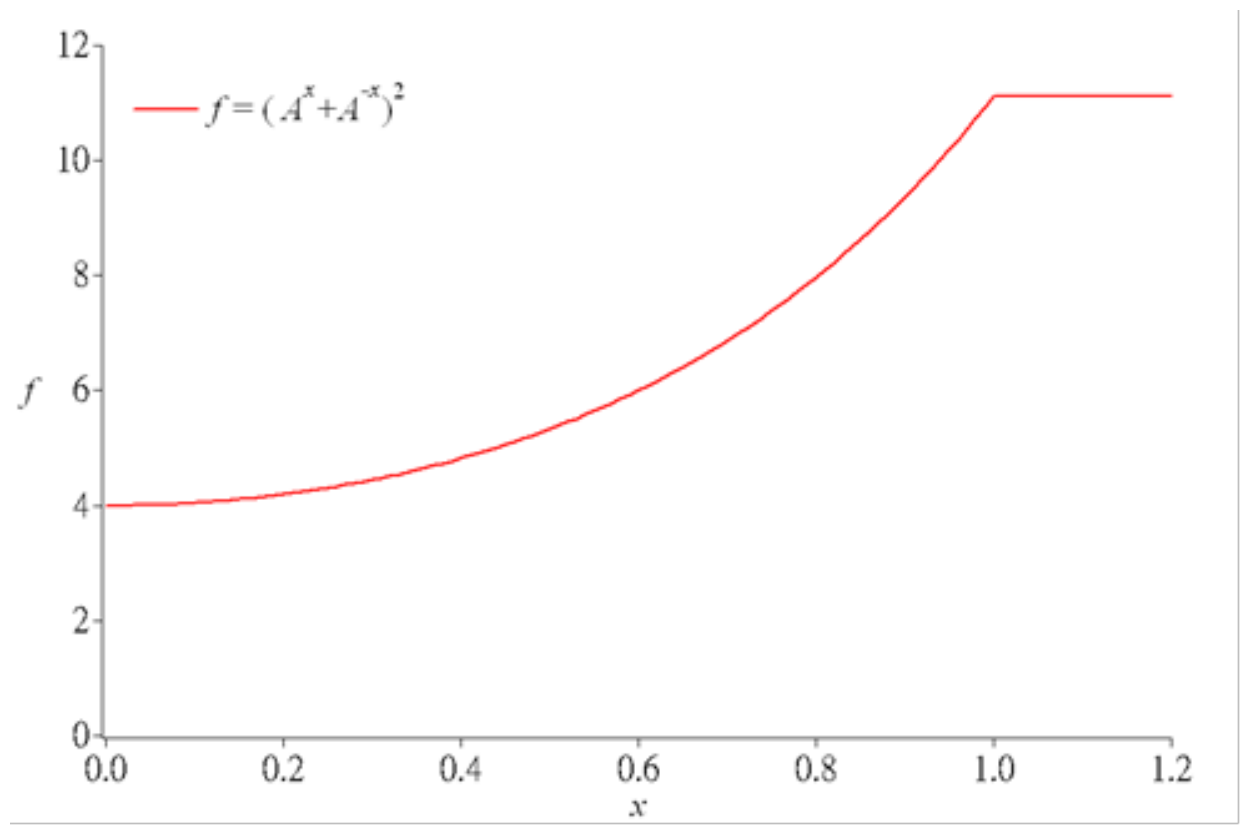

Fig. 10. Schematic showing the effect of amplification function

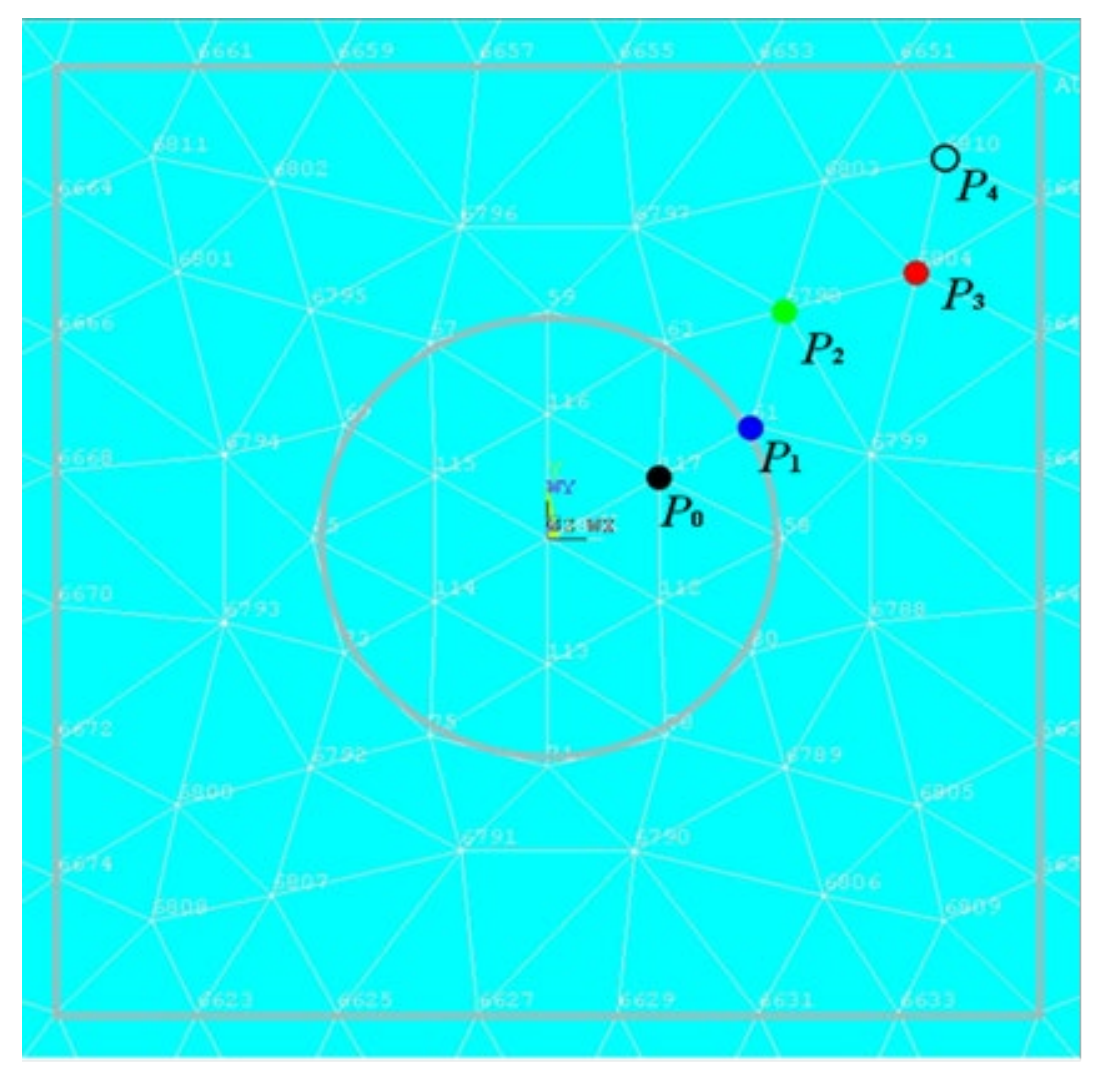

Fig. 11. Arrangement of multiple receivers on the top surface of a capped pile 


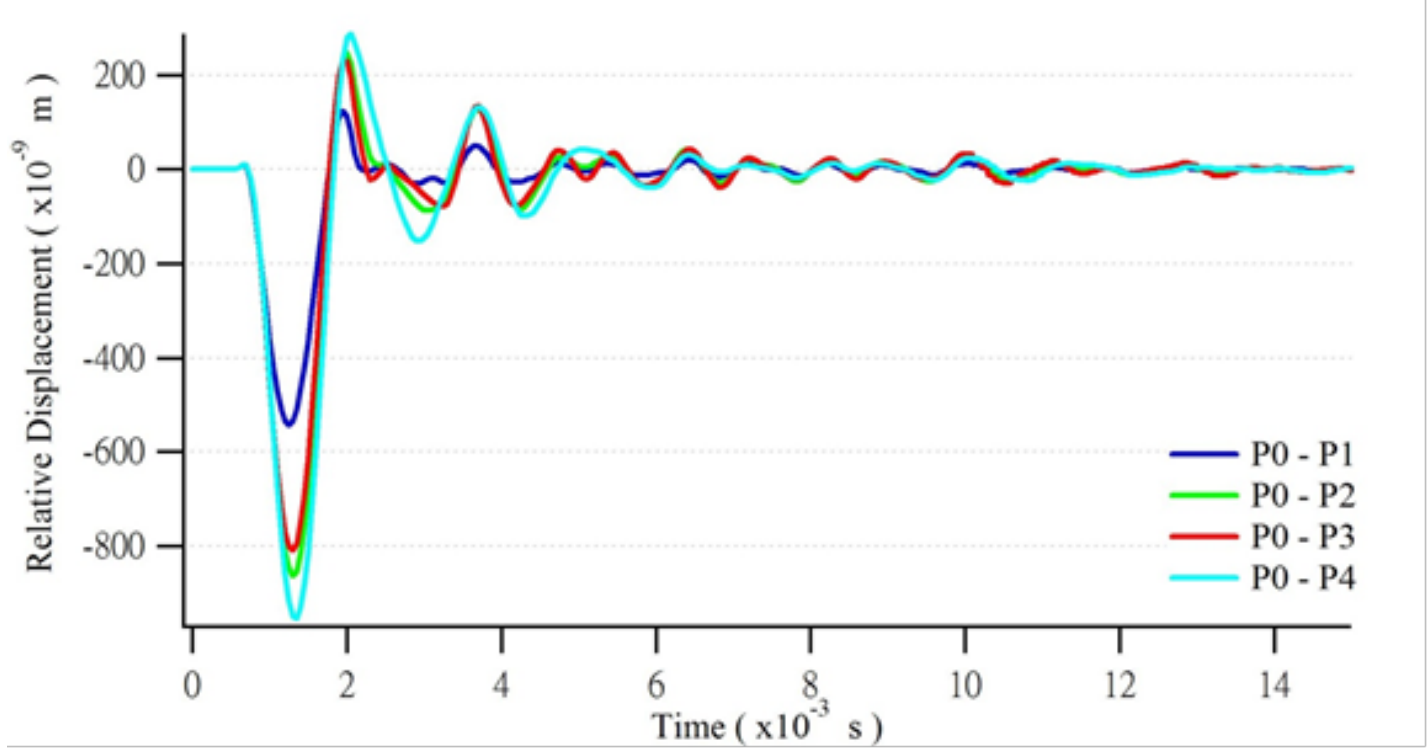

Fig. 12. Displacement differences obtained from different receiver pairs

amplitude usually implies the arrival of a possible reflection from an interface or boundary such as pile toe. After comparison, the most significant reflection can be found in Fig. 13 (d) at the time $t=8.8 \mathrm{~ms}$, which corresponds to a travel distance of $33.4 \mathrm{~m}$ if the wave velocity is $3800 \mathrm{~m} / \mathrm{s}$. Considering that the thickness of the cap is $2.5 \mathrm{~m}$, the length of the underneath pile can be estimated to be $14.2 \mathrm{~m}$. The error is only $1.4 \%$ for the designed length of $14 \mathrm{~m}$. Although the pile length is only $14 \mathrm{~m}$ for this case, however, the analysis may be very complicated if the target to be tested is a capped pile. The obvious benefit can easily be seen as we compare the results shown in Fig. 13 (d) and Fig. 8, which resulted from an in situ SE test over a pile group with similar geometric configuration. Without the assistance of the proposed scheme, the analysis work often becomes infeasible, as shown in Fig. 8.

Another point to be noted is that a velocity sensor is usually used in the SE test and thus the analysis work is frequently done using the velocity signals. However, it is not too difficult to obtain the corresponding displacement signals through integration over time. In this research, the initial thought for using displacement instead of velocity signals was to reduce the unwanted noisy fluctuations. Usually displacement signals exhibit smoother behavior than velocity ones. In our proposed scheme, the testing results should go through a process of subtraction before they are used to be sought for the possible reflection signals. To have a smoother resultant curve for analysis, displacement may be a better choice. This thought was verified through Fig. 14 (a) and (b), which are the original and amplified velocity differences corresponding to the displacement counterparts shown in Fig. 13 (a) and (d). The velocity signals shown in Fig. 14 (b) reveal more noisy fluctuations of higher frequency than the displacement signals in Fig. 13 (d).
Through the results discussed above, however, it should be noted that it is only a result of numerical simulation because the idea of using multiple receivers and the proposed scheme originated after the test of Fig. 8 was done. And therefore the proposed scheme still needs further incubation efforts to pass through strict experimental verifications before it can be extensively applied in practice. To carry out a preliminary check on the feasibility of the proposed scheme, a field test on a miniature pile group was fulfilled and the result follows.

\section{RESULTS OF IN-SITU TEST}

To verify the feasibility of the proposed scheme, a field test on a miniature pile group were carried out. Fig. 15 shows two pile groups. Each pile group is supported by three piles. The pile cap is $214 \times 50 \mathrm{~cm}$ in the horizontal plane, and $30 \mathrm{~cm}$ high. The diameter of each pile is $30 \mathrm{~cm}$ and its length is $3 \mathrm{~m}$ beneath the bottom surface of the cap. The first pile was selected for the test. The hammer impact was applied on the top surface of the pile cap at the center of the circular area on which the beneath pile projects. At the first impact, the receiver was placed only $5 \mathrm{~cm}$ away from the impacting point. This location is denoted by $P a$ as shown in Fig. 15. Later the receiver was moved to the location $\mathrm{Pb}$ on the top surface of the cap at the mid length of a line connecting two centers of the circular areas on which the beneath piles project. Measuring from the rightmost border line of the cap, the distance to $\mathrm{Pa}$ and $\mathrm{Pb}$ are $21 \mathrm{~cm}$ and $56 \mathrm{~cm}$, respectively. The velocity responses at $P a$ and $P b$ after the impact are presented with blue and green curves respectively in Fig. 16. To rule out the difference in starting time at two receivers and the difference in force amplitude at two impacts, the response at $P b$ is shifted forward in time by $3.71 \mathrm{~ms}$ and its amplitude is factored with the ratio of the largest amplitudes recorded 


\section{International Journal of Applied Science and Engineering}

Liao et al., International Journal of Applied Science and Engineering, 18(3), 2021028

(a)

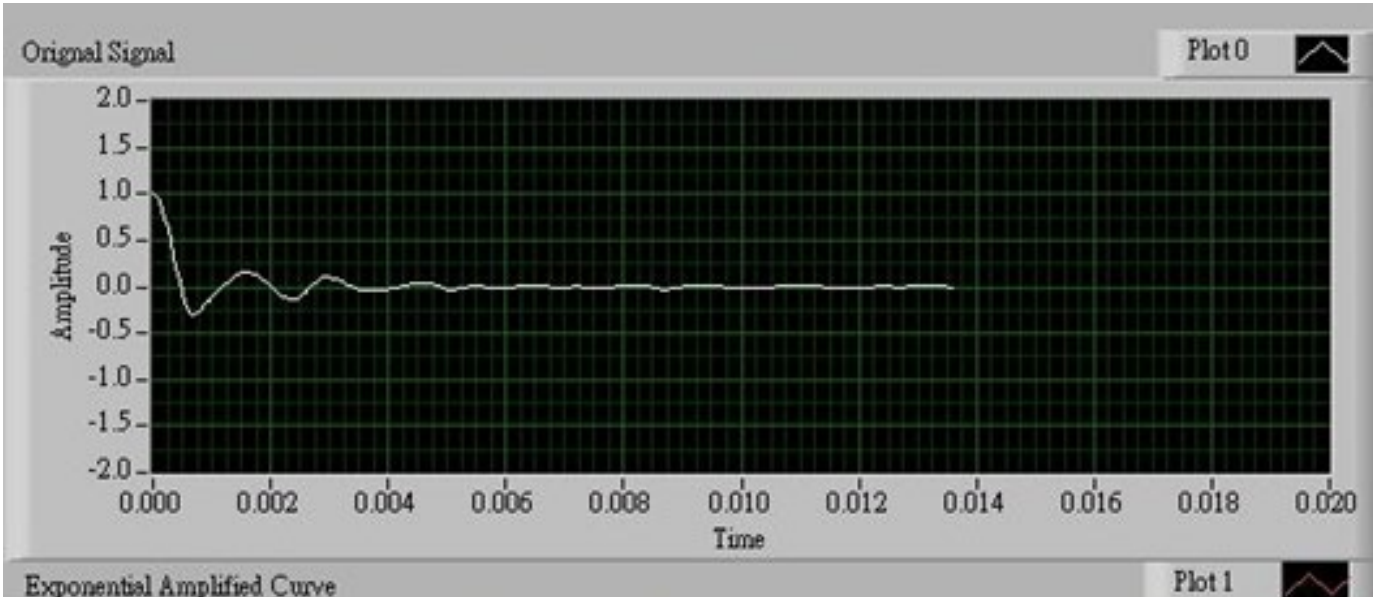

(b)

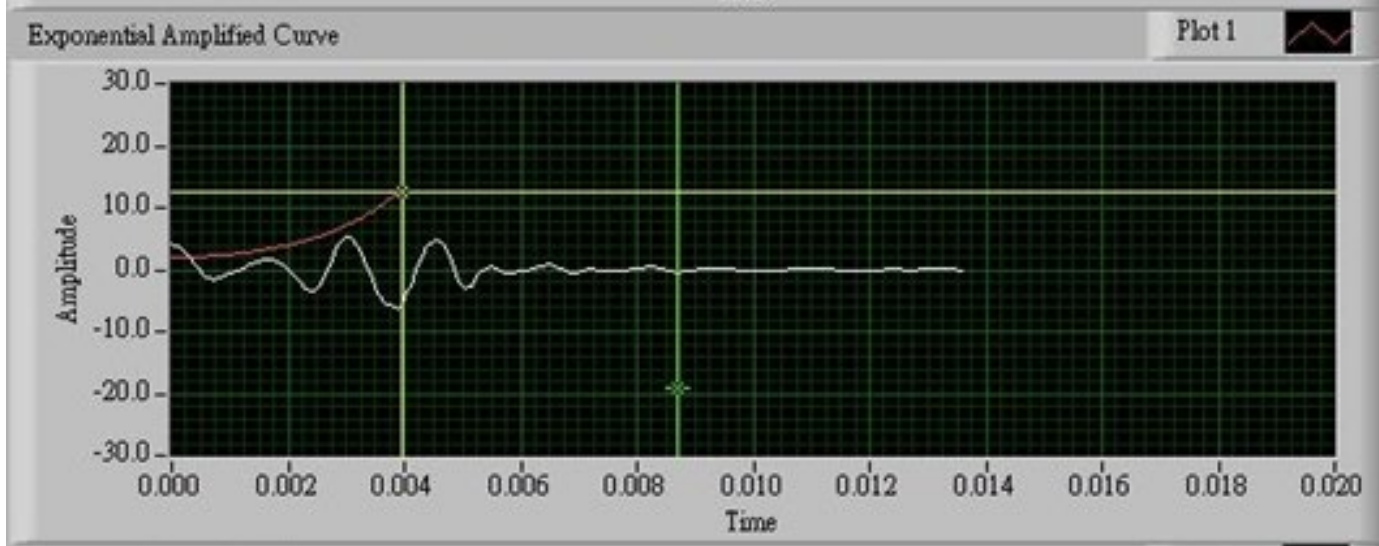

(c)

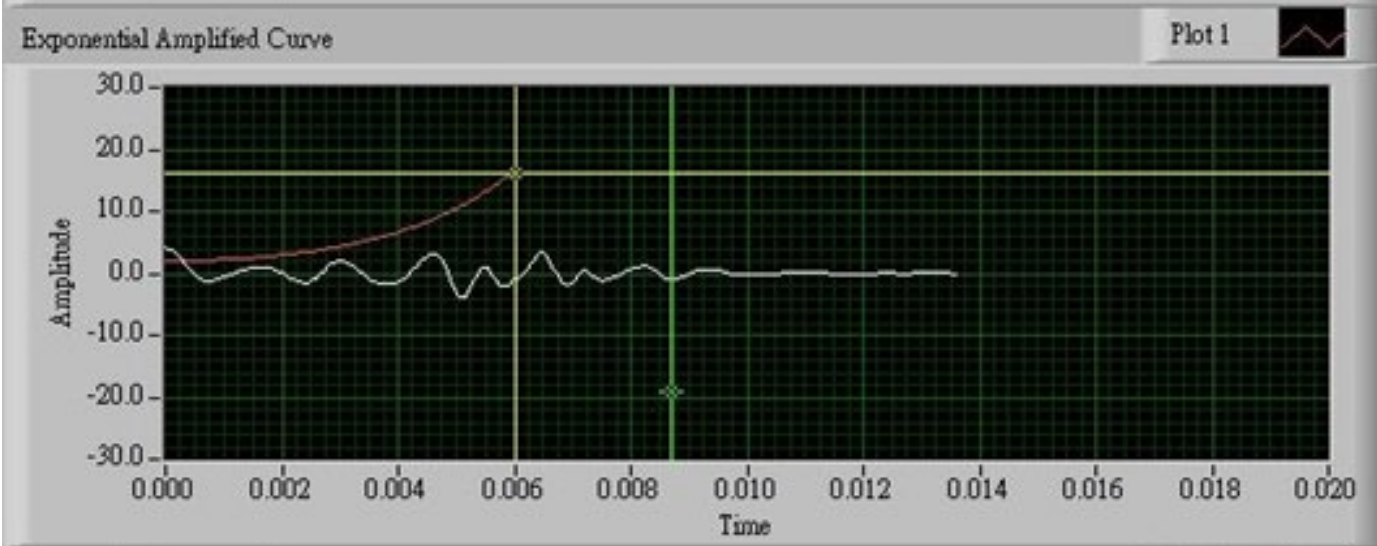

(d)

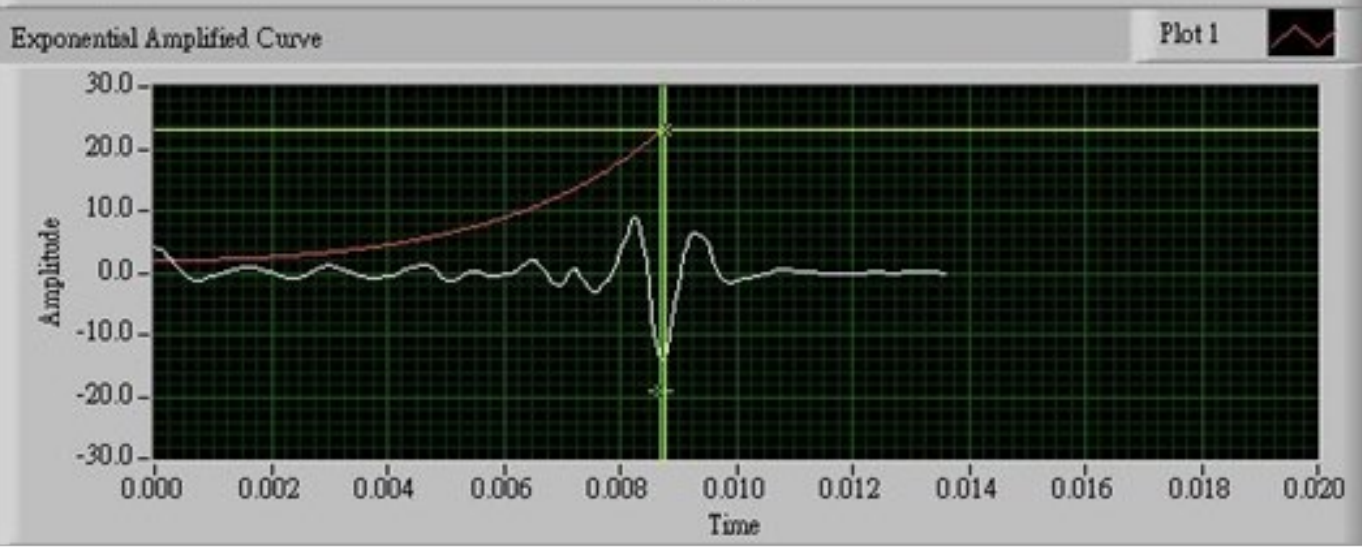

Fig. 13. (a) The original displacement difference and its amplified counterparts with the times of the control points being set at (b) 4, (c) 6, and (d) $8.8 \mathrm{~ms}$ 


\section{International Journal of Applied Science and Engineering}

Liao et al., International Journal of Applied Science and Engineering, 18(3), 2021028

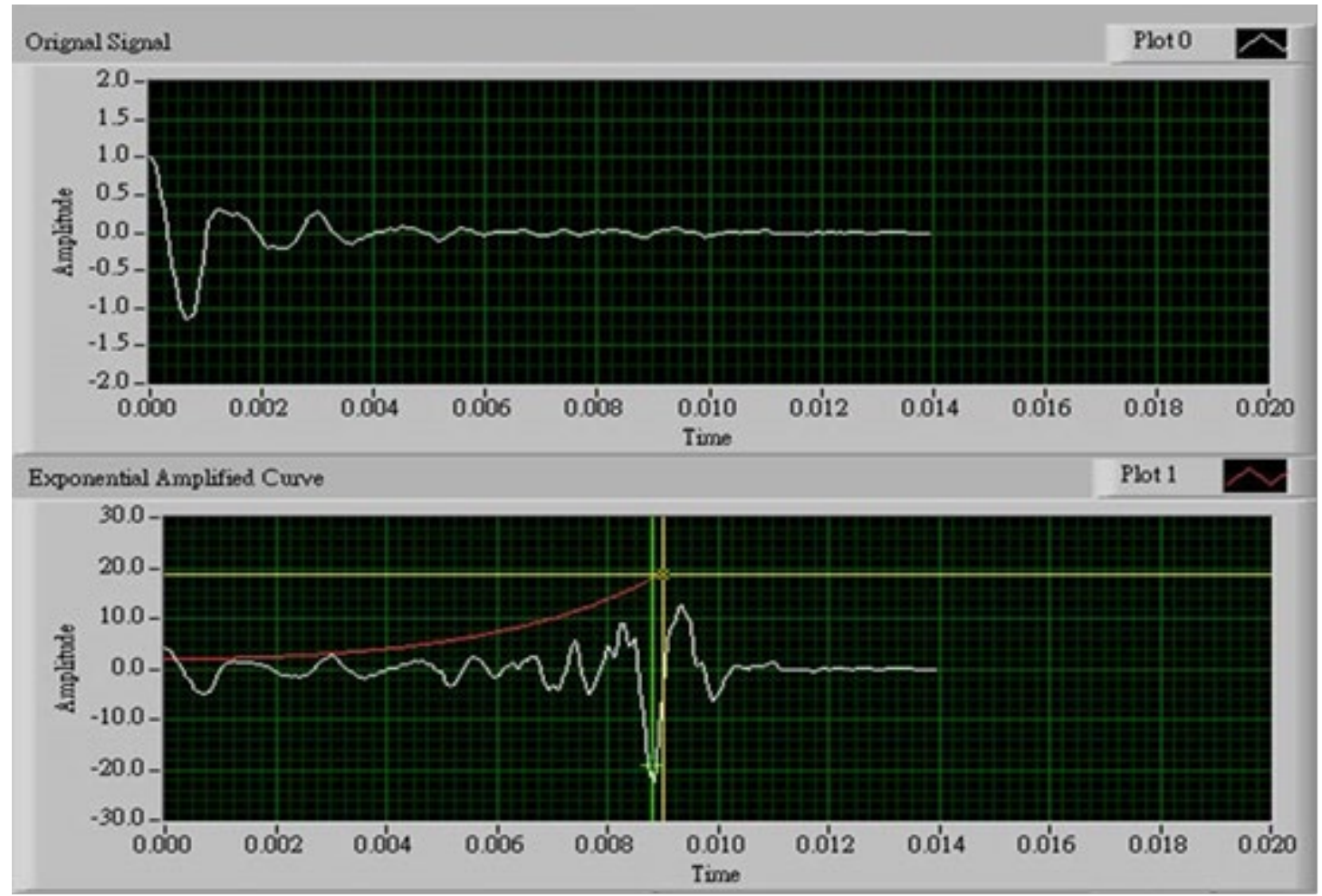

Fig. 14. Velocity differences obtained from different receiver pairs

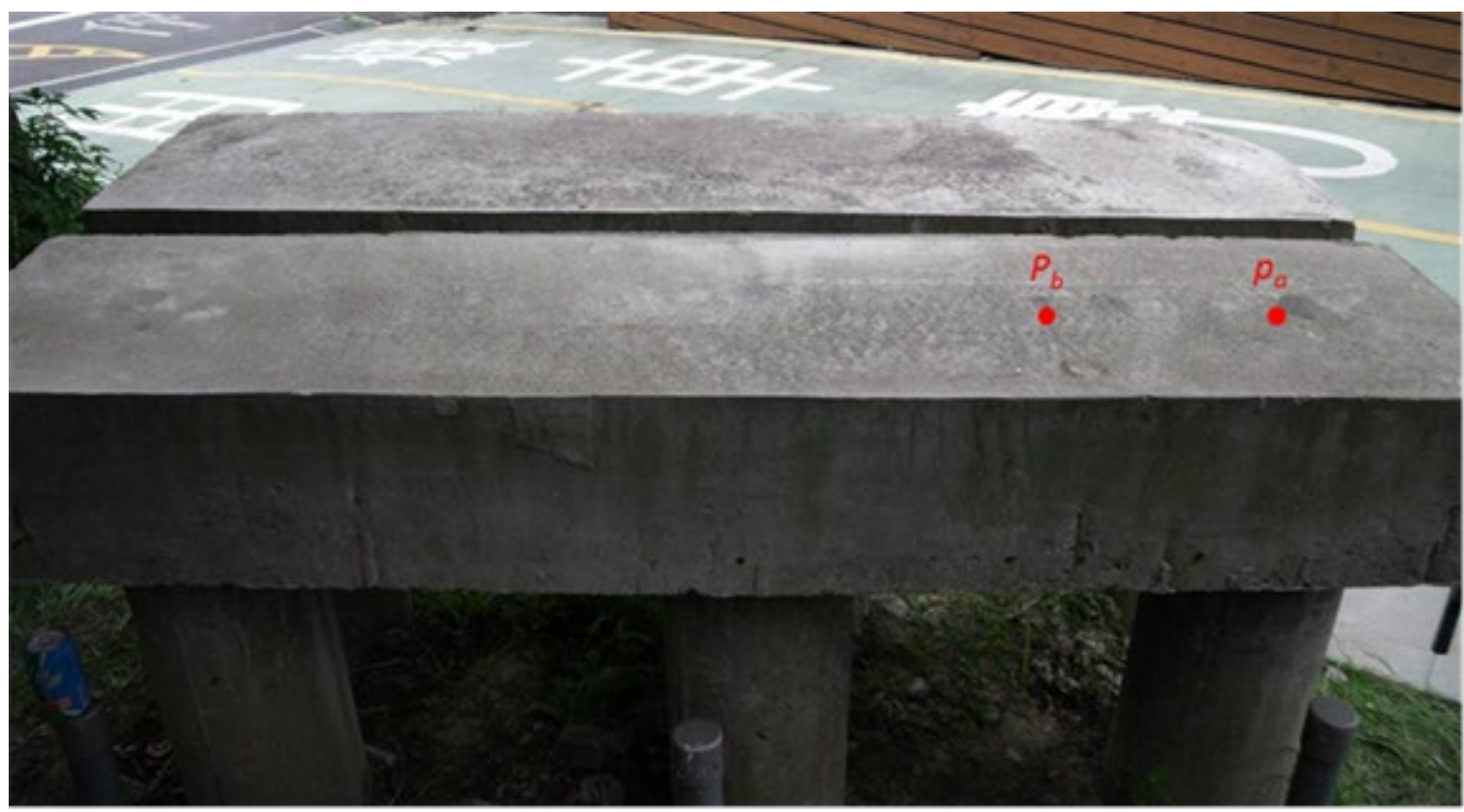

Fig. 15. Photo of a miniature pile group to be tested in the field 


\section{International Journal of Applied Science and Engineering}

Liao et al., International Journal of Applied Science and Engineering, 18(3), 2021028

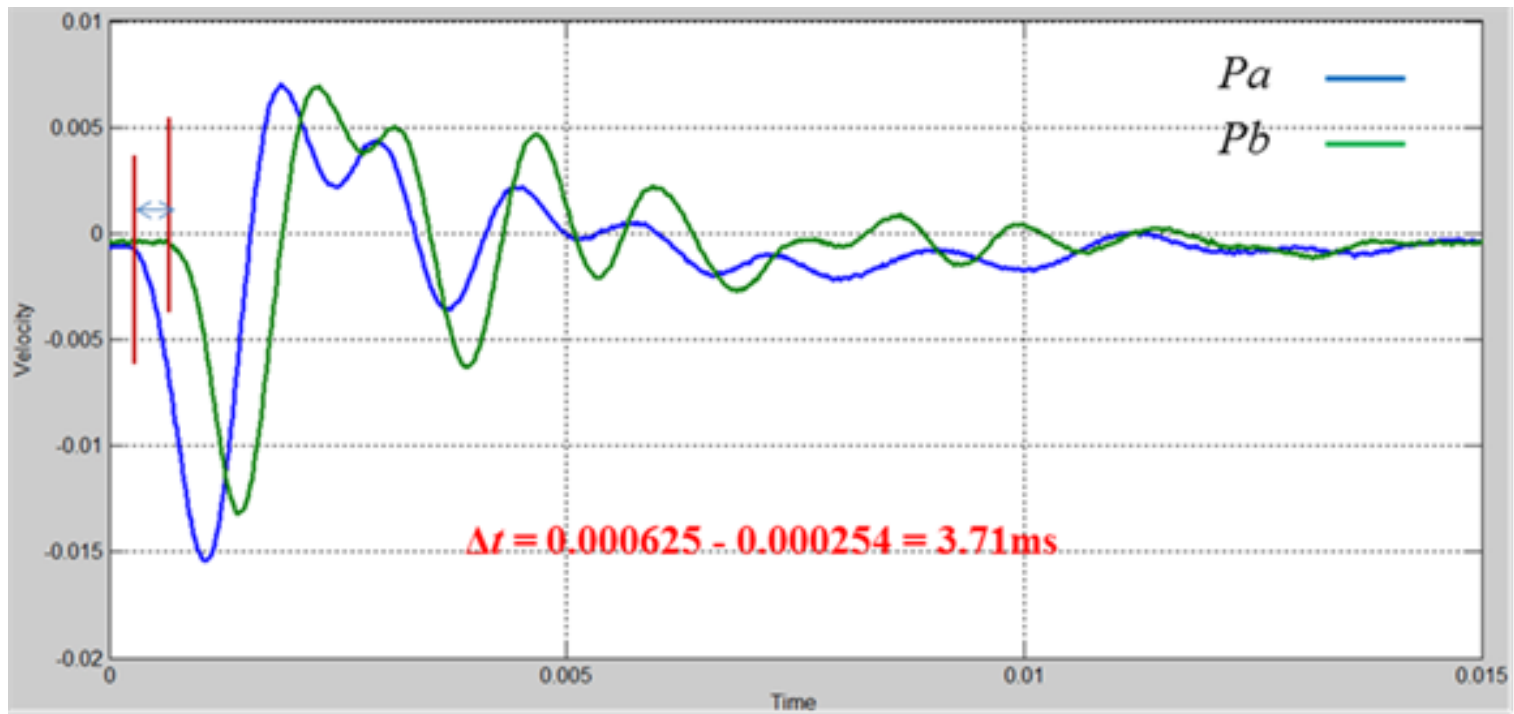

Fig. 16. Velocity responses obtained at two locations on the pile group in the field

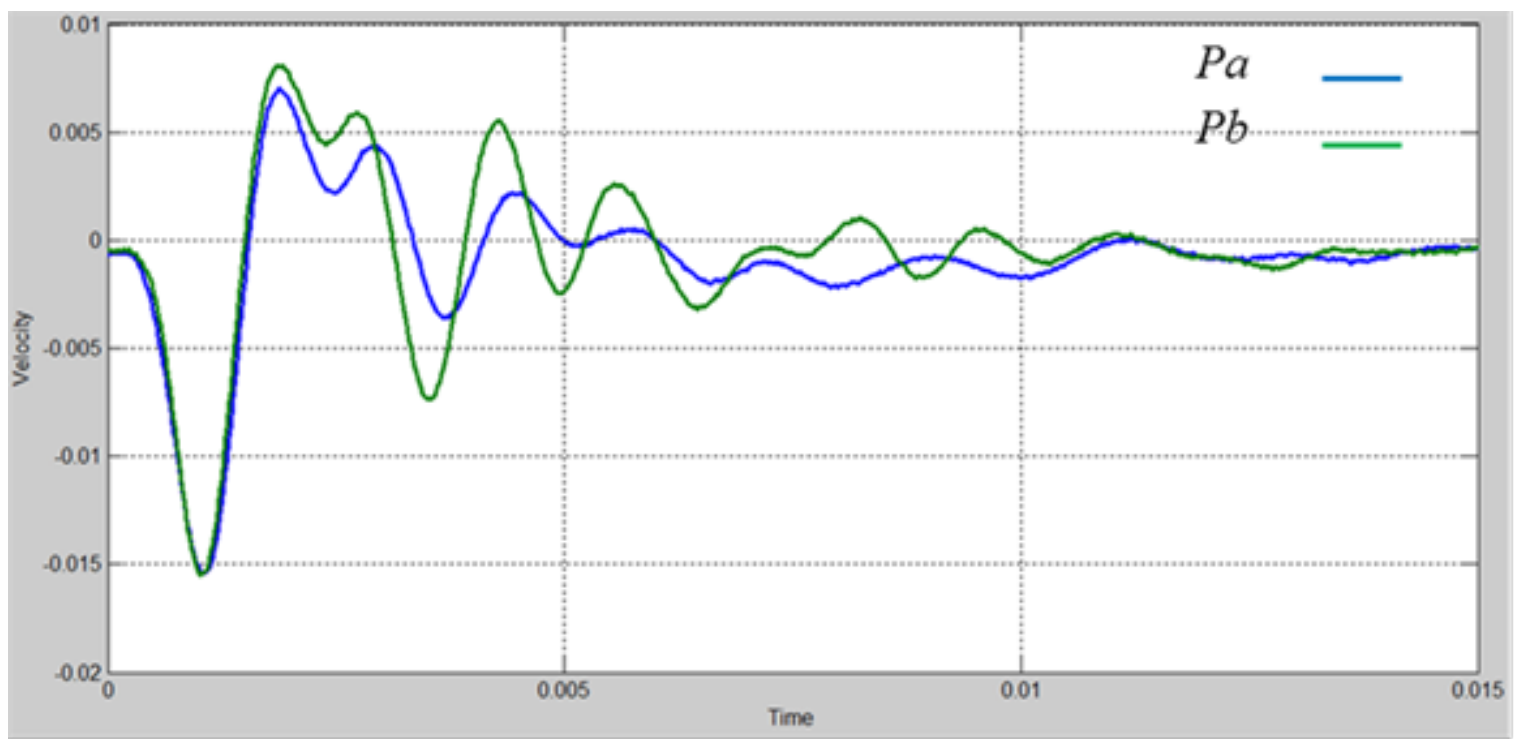

Fig. 17. Velocity responses after shifting and normalization at two receivers

by the two receivers. The result is presented in Fig. 17. The proposed scheme is then carried by subtracting these curves and the result is presented in Fig. 18. From the velocity difference shown in this figure, the reflection from the pile toe is so clearly observed that the travel time of one trip can be easily determined to be $2.32 \mathrm{~ms}$ by use of the largest peaks in the force input and in the response difference. Knowing the wave velocities in the cap and in the pile, the predicted pile length is $3.7 \mathrm{~m}$, which is $23 \%$ in error.

\section{CONCLUSIONS}

In this paper the profound difficulty in analyzing the results of a sonic echo test on a capped pile is illustrated by an in situ test on a bridge foundation before and after the pile was capped. A theoretical possible way to evaluate the length of a capped pile in a pile group with nondestructive testing techniques is then proposed. The idea of this new method is to integrate the traditional sonic echo test with the use of multiple receivers and signal amplification so that identifying the reflections from pile toe may become feasible and reliable. The basic philosophy of this scheme is to reduce or eliminate the interferences from the cap by subtracting the response signals recorded in the receivers and then amplify the differenced results to search for possible reflections. The capability of this scheme is preliminarily verified by numerical simulation with finite element model and a field test on a miniature pile group. Therefore, further experimental verifications and incubation efforts are required before it can be extensively applied in practice. It can be expected that the environment and device factors may play a key role in the success of applying this 


\section{International Journal of Applied Science and Engineering}

Liao et al., International Journal of Applied Science and Engineering, 18(3), 2021028

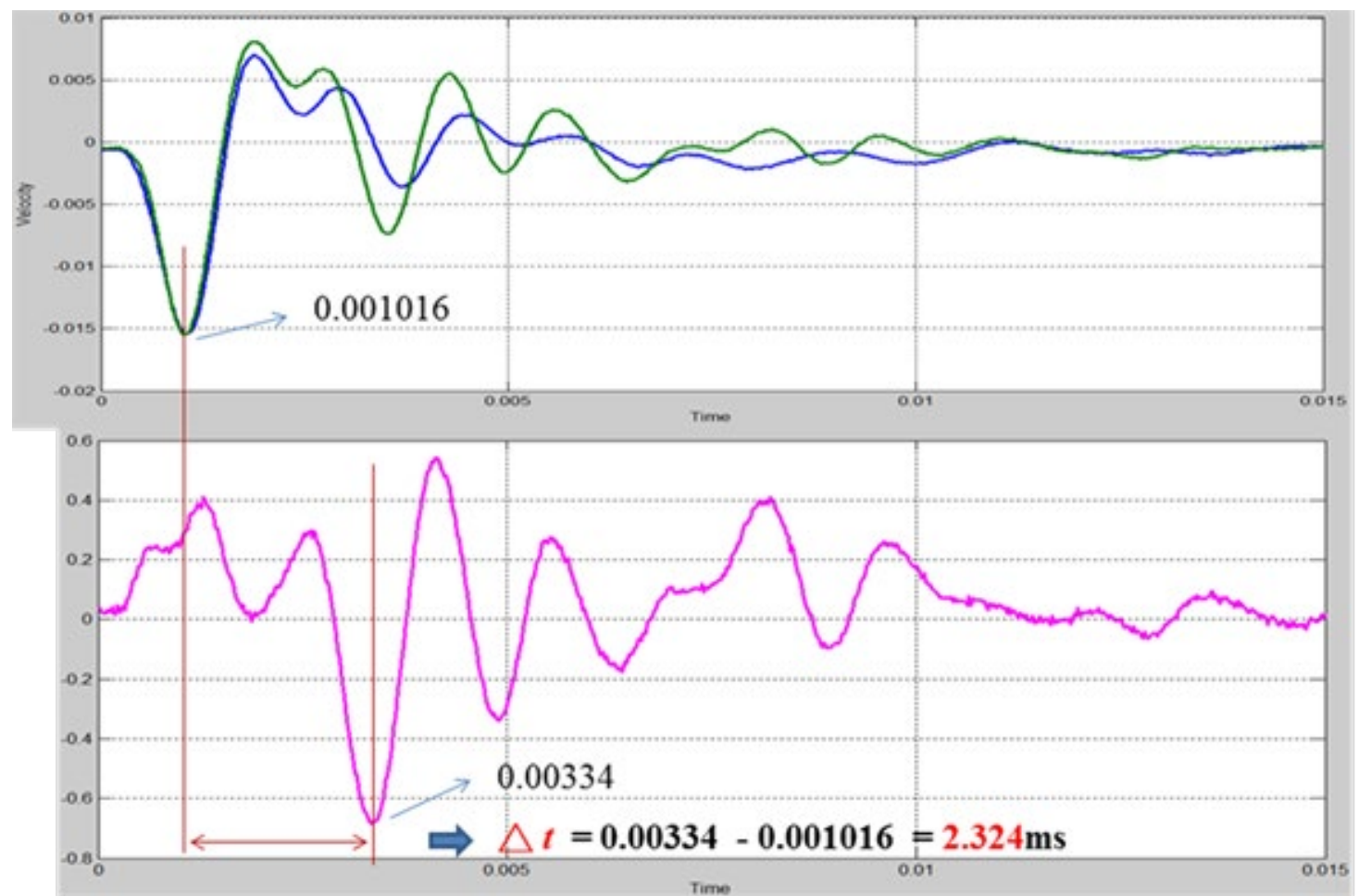

Fig. 18. Shifted and normalized velocity responses at two receivers and their difference

method to practice because that this method involves the subtraction of the recorded signals. Any adverse conditions, such as the noises from interface bonding or electrical circuiting of the receivers, may tremendously affect the results of analysis.

The normalization and phase shift among receivers may be other problems to be overcome. Nevertheless, this paper has exposed the promising potential of this new method in providing a solution to the length evaluation of capped piles with NDT techniques.

\section{ACKNOWLEDGEMENTS}

The authors thank the Ministry of Science and Technology of Taiwan for the financial support through Grants MOST 105-2918-I-216-001 and MOST 109-2221E-005-002.

\section{REFERENCES}

ASTM book of standards, 2004. D5882, 04.09.

Baker, C.N., Jr., Drumright, E.E., Mensah, F.D., Parikh, G., Ealy, C.D. 1991. Use of nondestructive testing to evaluate defects in drilled shafts: Results of FHWA research. Integrity Testing of Foundations, Transportation Research Record, 1331, 28-35.

Baxter, S.C., Islam, M.O., Gassman, S.L. 2004. Impulse response evaluation of drilled shafts with pile caps: Modeling and experiment. Canadian Journal of Civil Engineering, 31, 169-177.
Chow, Y.K., Phoon, K.K., Chow, W.F., Wong, K.Y. 2003. Low strain integrity testing of piles: Three-Dimensional effects. Journal of Geotechnical and Geoenvironmental Engineering, ASCE, 129, 1057-1062.

Davis, A.G. 2003. The nondestructive impulse response test in North America: 1985-2001. NDT\&E International, 36, 185-193.

Finno, R.J., Gassman, S.L. 1998. Impulse response evaluation of drilled shafts. Journal of Geotechnical and Environmental Engineering, ASCE, 124, 965-975.

Gassman, S.L., Finno, R.J. 1999. Impulse response evaluation of foundation using multiple geophones. Journal of Performance of Constructed Facilities, ASCE, $13,82-89$.

Gassman, S.L., Finno, R.J. 2000. Cutoff frequencies for impulse response tests of existing foundations. Journal of Performance of Constructed Facilities, ASCE, 14, 11-21.

Guddati, M.N., Rahman, M.S., Samu, V. 2018. Improved estimation of embedded pile length for reuse or pile scour evaluation. NCDOT Project 2016-21, Report: FHWA/NC/2016-21.

Kim, D.S., Kim, H.W., Kim, W.C. 2002. Parametric study on the impact-echo method using mock-up shafts. NDT\&E International, 35, 595-608.

Lai, J., Yu, C.-P., Liao, S.-T. 2005. Assessment of integrity of piles by impedance log technique. Key Engineering Materials, 321-323, 340-343.

Liao, S.-T., Roesset, J.M. 1997. Dynamic response of intact piles to impulse loads. International Journal for Numerical and Analytical Methods in Geomechanics, 21, 255-275. 
Liao, S.-T., Tong, J.-H., Chen, C.-H., Wu, T.-T. 2006. Numerical simulation and experimental study of parallel seismic test for piles. International Journal of Solids and Structures, 43, 2279-2298.

Ni, S.-H., Tsai, P.-H., Yang, Y.-Z., Chou, W.-H. 2019. Improved approach for determining pile length of group pile using complex continuous wavelet transform, Journal of Testing and Evaluation; 47, 1920-1934. https://doi.org/10.1520/JTE20170720

Olson, L.D., Jalinoos, F., Aouad, M.F. 1995. Determination of unknown subsurface bridge foundations. Report submitted to NCHRP, Transportation Research Board, National Research Council, 129-148.

Rausche, F., Shen, R.K., Likins, G.E. Jr. 1991. Comparison of pulse echo and transient response pile integrity test methods. Integrity Testing of Foundations, Transportation Research Record, 1331, 21-17.

Tong, J.-H., Chiu, C.-L., Wang, C.-Y. 2010. Improved synthetic aperture focusing technique by Hilbert-Huang transform for imaging defects inside a concrete structure. IEEE Transactions on Ultrasonics, Ferroelectrics, and Frequency Control, 57, 2512-2521.

Tong, J.-H., Liao, S.-T., Lin, C.-C. 2007. A new ElasticWave-Based Imaging method for scanning the defects inside the structure. IEEE Transactions on Ultrasonics, Ferroelectrics, and Frequency Control, 54, 128-137.

Wang, H. 2020. A simple approach to determine pile lengths using flexural wave frequency spectrum information. Insight, 62, 357-364. DOI: 10.1784/insi.2020.62.6.357

Yu, C.-P. 2019. Evaluation of pile lengths using impactinduced flexural vibrations - A frequency domain approach. NDT\&E International, 108, 102174. https://doi.org/10.1016/j.ndteint.2019.102174

Yu, C.-P., Liao, S.T. 2006. Theoretical basis and numerical simulation of impedance log test for evaluating the integrity of columns and piles. Canadian Geotechnical Journal, 43, 1238-1248.

Yu, C.-P., Liao, S.-T., Kallivokas, L.F. 2020. An extension of the mobility analysis of the Impulse Response method for coupled pile-soil integrity testing. Journal of Earthquake Engineering, online Sep. 1-21. https://doi.org/10.1080/13632469.2020.1814451 